\title{
The kinetic product of the octabromination of p-tert-butylcalix[8]arene octamethyl ether
}

\author{
David Poms, Avia Leader, and Silvio E. Biali* \\ Institute of Chemistry, The Hebrew University of Jerusalem, Jerusalem 91904, Israel \\ E-mail: silvio.biali@mail.huji.ac.il
}
Dedicated to Michael Orfanopoulos (Department of Chemistry, University of Crete, Greece) on the occasion of his $67^{\text {th }}$ birthday

DOI: http://dx.doi.org/10.3998/ark.5550190.p008.781

\begin{abstract}
A new isomer, not previously detected, is the kinetic product of the octabromination (NBS, $\mathrm{CH}_{2} \mathrm{Cl}_{2}, \mathrm{rt}, 60 \mathrm{~W}$ Vis irradiation) of p-tert-butylcalix[8]arene octamethyl ether. On the basis of the signal pattern in the NMR spectrum, and the splitting of methoxy signals in the presence of a chiral solvating agent, the isolated product is assigned as one of the two possible achiral forms of $C_{s}$ symmetry, where the mirror symmetry operation bisects two opposite aryl rings.
\end{abstract}

Keywords: Calixarene, stereochemistry, configuration, chirality

\section{Introduction}

The "classic" calix[n]arenes are cyclic molecules consisting of an alternating array of phenol and methylene moieties. ${ }^{1-9}$ Several synthetic methods have been developed enabling the preparation of derivatives substituted at the bridges. ${ }^{10-18}$ Calixarenes monosubstituted at all bridges by bromine atoms (5-8) are useful compounds for the preparation of calixarenes derivatives with a wide array of substituted bridges. ${ }^{19-23}$ These bromo derivatives can be prepared via photochemical bromination of the corresponding calixarene methyl ethers $\mathbf{1 - 4} .^{19-22,24-26}$ 


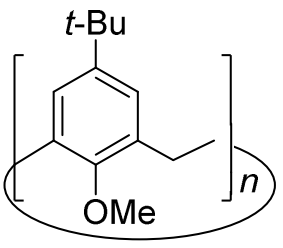

1: $n=4$

2: $n=5$

3: $n=6$

4: $n=8$

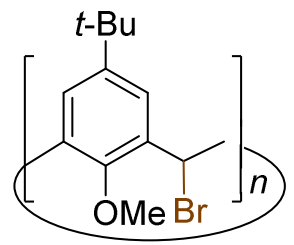

5: $n=4$

6: $n=5$

7: $n=6$

8: $n=8$

The hexabromocalix[6]arene derivative 7 reacts with a variety of $\mathrm{O}_{-}, \mathrm{N}-$, and even $\mathrm{C}$ nucleophiles under $S_{N} 1$ conditions affording a wide array of methylene-functionalized calix[6]arenes derivatives. For example, heating to reflux a mixture of 7, 2,4-pentanedione and hexafluoroisopropanol (HFIP) yields the derivative 9 in a reaction involving sixfold C-C bond formation (Eq. 1). ${ }^{21}$

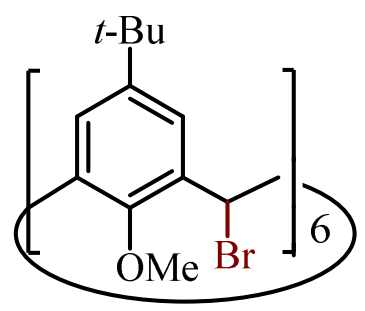

7
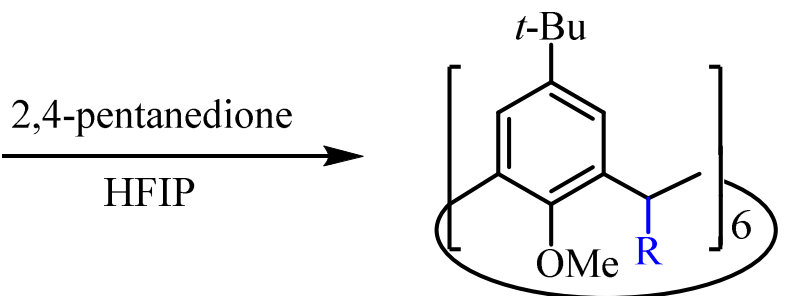

9<smiles>[R]=CC(C)C(C)=O</smiles>

Due to the presence of stereocenters (the monosubstituted bridges), several stereoisomeric products may be possible for both the bromocalixarene starting material and the reaction product. These isomers arise from the relative cis or trans disposition of pairs of substituents at adjacent bridges. Hexabromocalix[6] arene $\mathbf{7}$ is obtained in the bromination step exclusively as the all-cis form, and its reactions with nucleophiles also afford the all-cis derivatives. ${ }^{21}$

Bromination of the octamethyl ether of p-tert-butylcalix[8]arene 4 with excess NBS under irradiation has been reported to afford a major octabromo product $8{ }^{25}$ The NMR spectrum of this product consisted of a very simple pattern of signals (single singlets for the aromatic, methine, methoxy and $t$-Bu groups). ${ }^{25}$ In principle, eighteen isomers are possible for 8 (see Figure 1) resulting from the cis or trans dispositions of the bromines on the bridges. ${ }^{27}$ The spectrum reported (assuming fast rotations of the aryl rings on the NMR timescale) indicates a molecule of high symmetry, and is consistent only with the all-cis or all-trans isomers. 
We conducted the bromination of $\mathbf{4}$ with NBS in both $\mathrm{CCl}_{4}$ and $\mathrm{CH}_{2} \mathrm{Cl}_{2}$ and, in our hands, in both cases the product consisted in a nearly identical mixture of octabromo derivatives. ${ }^{27}$ The major isomer displayed four doublets for the aromatic protons, three signals in a 2:4:2 ratio for the methine protons, and two singlets for the $t$-Bu groups, in agreement with structure $8 \mathbf{i}$ (i.e., of $\mathrm{rt}_{3} \mathrm{Ct}_{3}$ configuration). This major isomer could be isolated by trituration of the mixture with cold isopropanol. A partial characterization of the rest of the isomers was performed based on the pattern of signals in the ${ }^{1} \mathrm{H}$ NMR spectrum. ${ }^{27}$

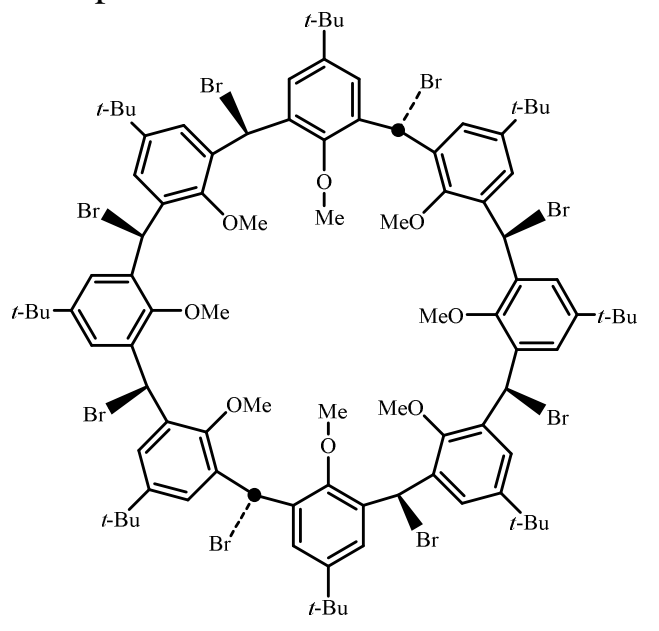

$8 \mathbf{i}$

Upon standing in $\mathrm{CDCl}_{3}$ solution, $8 \mathbf{i}$ isomerized to a mixture of isomers identical to that obtained in the crude mixture of brominated products. This indicates that the mixture obtained in the bromination in our hands is an equilibrium mixture of stereoisomers. Reaction of $\mathbf{8 i}$ or the isomeric mixture with $p$-xylene afforded identical products: a calix[8]arene derivative with the eight bridges monosubstituted by xylyl groups. ${ }^{27}$ 


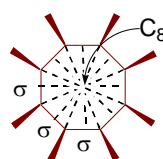

$8 a$

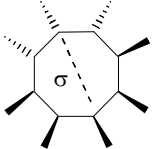

$8 f$

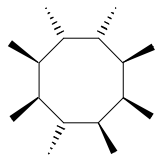

$8 \mathrm{k}$

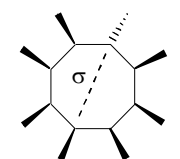

$8 b$

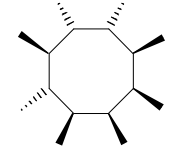

$8 \mathrm{~g}$

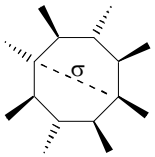

81

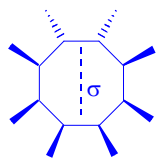

$8 \mathrm{c}$

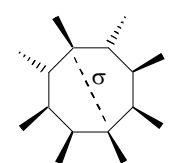

$8 \mathrm{~h}$

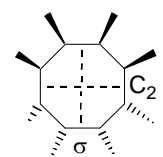

$8 \mathrm{~m}$

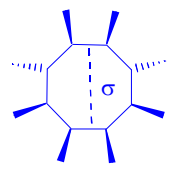

8d

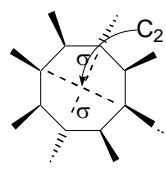

$8 \mathbf{i}$

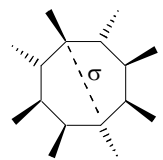

$8 n$

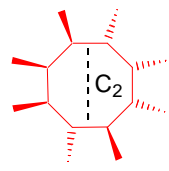

$8 e$

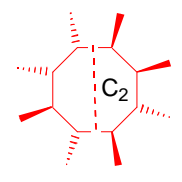

8j

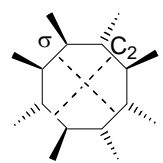

80

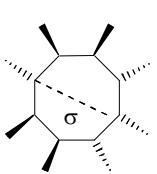

$8 p$

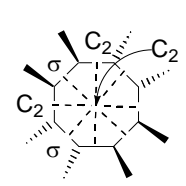

$8 q$

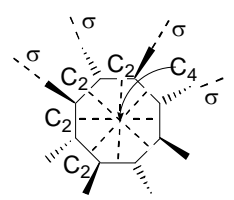

$8 r$

Figure 1. Schematic representation of the eighteen possible diastereomeric forms of octabromocalixarene $\mathbf{8}$ (for the chiral forms, only one enantiomer is depicted). The edges and vertices of the octagon represent the rings and substituted bridges, respectively. Structures in blue and red possess a single symmetry element (mirror plane or $\mathrm{C}_{2}$ axis, respectively) bisecting a pair of opposite rings.

Recently, we repeated the bromination reaction in $\mathrm{CH}_{2} \mathrm{Cl}_{2}$, and surprisingly obtained a single isomer of the octabromo derivative, not detected in the mixture of isomers previously obtained. This work was conducted to attempt to characterize this new product.

\section{Results and Discussion}

We performed the reaction of $\mathbf{4}$ with NBS in dichloromethane (room temperature) with overnight irradiation of a $60 \mathrm{~W}$ lamp. Examination of the crude product obtained indicated the formation of a new single octabromo product, not previously observed (by NMR) in the equilibrium mixture of isomers. Bromination of $\mathbf{4}$ in $\mathrm{CCl}_{4}$ under reflux conditions resulted in the equilibrium isomeric mixture previously observed. Increasing the power of the lamp to $150 \mathrm{~W}$ (which heated the solution to reflux) resulted also in the formation of the new isomer, although some isomerization was observed as well. This product was also different from the highly symmetric isomer reported 
in the literature. ${ }^{25}$ Examination of a sample of the product in $\mathrm{CDCl}_{3}$ after standing in the NMR tube for four days at room temperature indicated its complete isomerization into the equilibrium mixture of octabromo isomers. The isomerization of this product was significantly slower in $\mathrm{C}_{6} \mathrm{D}_{6}$. This isomerization, which most likely involves reversible heterolytic cleavage of the $\mathrm{C}-\mathrm{Br}$ bonds, is facilitated by the more polar chloroform solvent.

The new product displayed five signals for the $t$-Bu groups, five signals for the methoxy groups (both groups of signals in a 2:2:2:1:1 ratio), four singlets for the methine groups, and two singlets and five doublets (one doublet with double intensity) for the aromatic protons (Figure 2). This pattern of signals is consistent with an octabromocalix[8]arene derivative possessing a single symmetry element (mirror plane or $C_{2}$ axis) bisecting two opposite rings. From the structures displayed in Figure 1, only the pair of structures in red (8e and $\mathbf{8 j})$ and the pair of structures in blue (8c and $\mathbf{8 d}$ ) possess those symmetries. The two structures in red are chiral, while the two structures in blue are achiral forms.
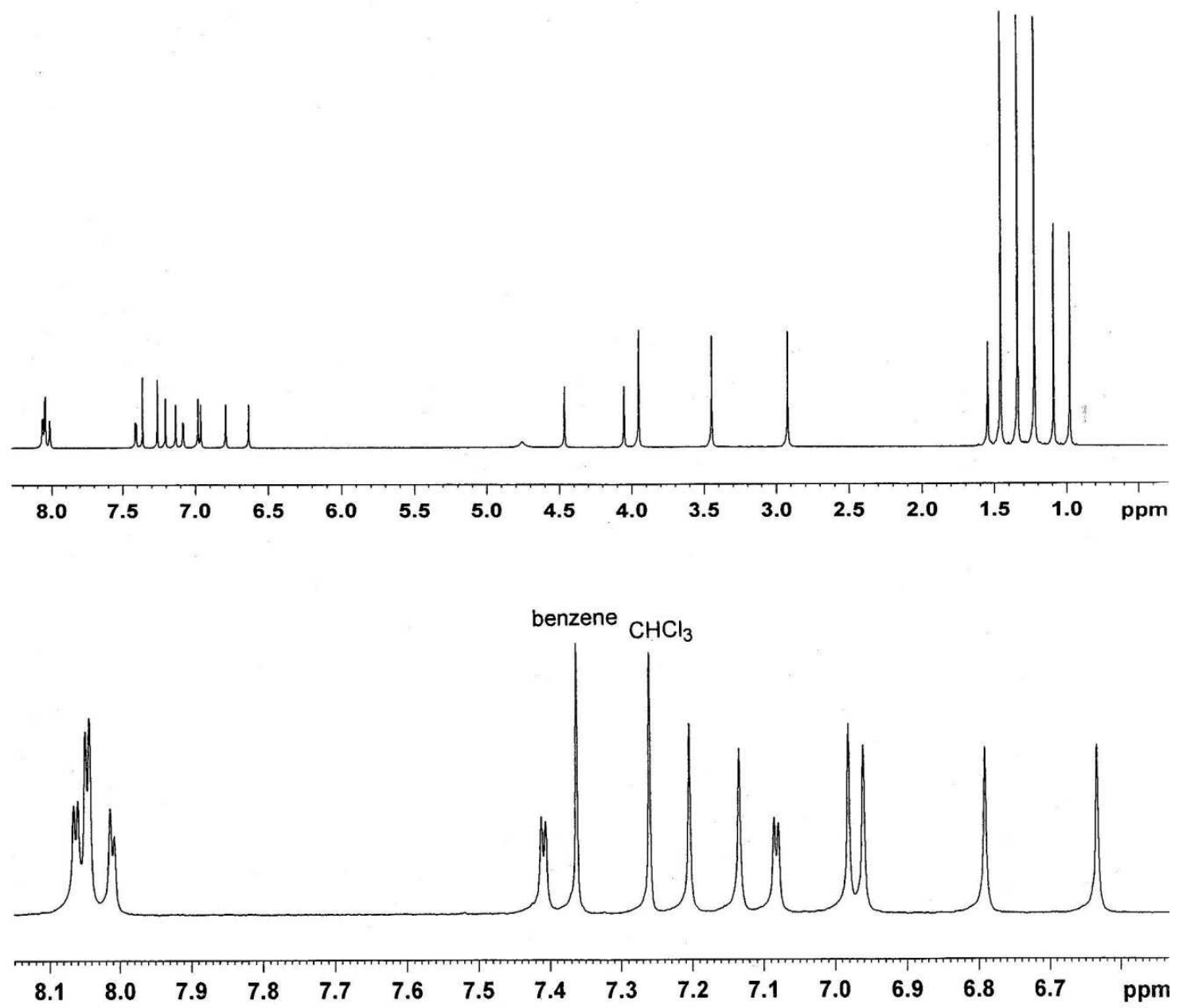

Figure 2. Top: ${ }^{1} \mathrm{H}$ NMR spectrum $\left(400 \mathrm{MHz}, \mathrm{CDCl}_{3}\right.$, rt) of the kinetic product of the bromination of 4 . Bottom: expansion of the methine and aromatic regions. 
In an attempt to ascertain whether the configuration of the kinetic product isolated corresponds to either the chiral or achiral structures, the NMR spectrum was determined in $\mathrm{C}_{6} \mathrm{D}_{6}$ in the presence of a chiral solvating agent. In principle, the chiral and achiral forms may be distinguished by the different splitting of the methoxy signals in a chiral medium. Since the bromination step was conducted under symmetric (achiral) conditions, if the kinetic product corresponds to one of the two chiral forms in red, both enantiomers of the form should be present (i.e., a racemic mixture). In the chiral forms, pairs of methoxy groups related by the $\mathrm{C}_{2}$ symmetry operation are homotopic. In addition, a methoxy group of a given enantiomer is mirror-related to a methoxy in the enantiomeric form and therefore the two are enantiotopic by external comparison. This is schematically shown in Figure 3 for isomer 8e, where letters (a-e) represent different magnetic sites for the methoxy groups, identical letters represent homotopic groups (e.g., the two methoxy groups designated as "b" in the left structure) and letters in italics represent groups that are enantiotopic to the corresponding non-italicized letters (e.g., $\mathrm{b}$ and $b$ are enantiotopic groups).

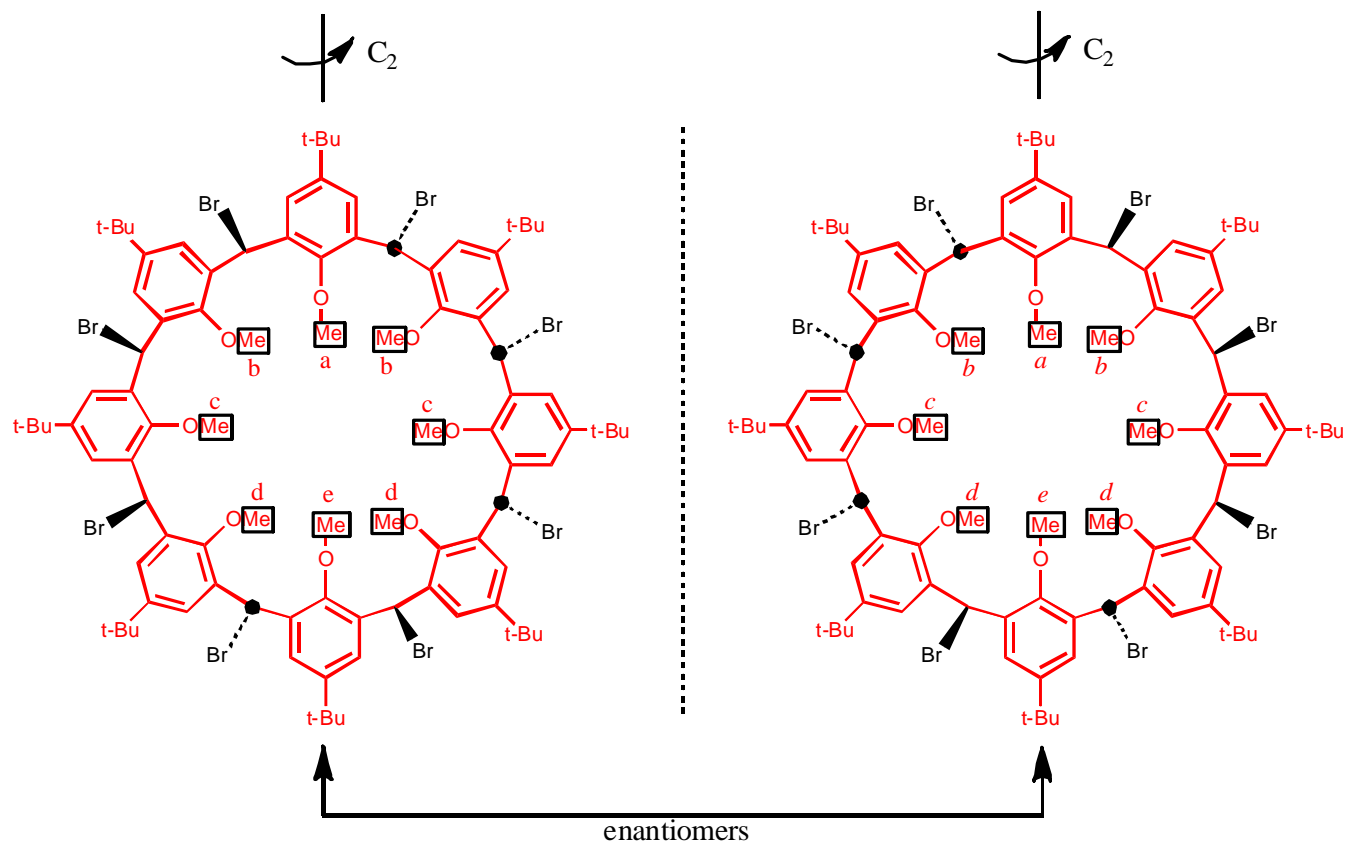

Figure 3. Homotopic and enantiotopic groups in the chiral isomer $\mathbf{8 e .}$

Since enantiotopic groups can be differentiated in the NMR in a chiral (and non-racemic) medium, each of the five methoxy signals is expected to split into two signals of equal intensity, affording a total of ten signals in the presence of the chiral solvating agent. Similarly, ten signals are expected in the NMR for a racemic mixture of $\mathbf{8 j}$ in a chiral medium. 


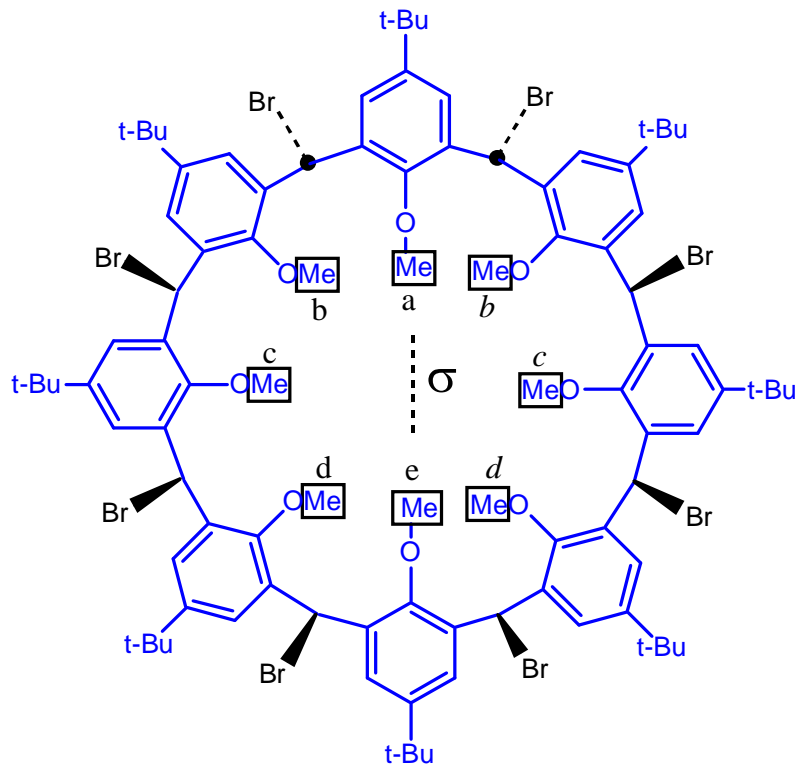

Figure 4. Homotopic and enantiotopic groups in the achiral isomer 8c.

In the two achiral forms $\mathbf{8 c}$ and $\mathbf{8 d}$, only the three pairs of methoxy groups related by the mirror symmetry, are pairwise enantiotopic (by internal comparison). This is exemplified for $\mathbf{8 c}$ in Figure 4. In the presence of a chiral solvating agent these pairs of enantiotopic groups are expected to become anisochronous, resulting in a total of only eight signals. Signals corresponding to the three pairs of enantiotopic methoxy groups should be readily identified since each of these signals should possess integrations twice as large as the integration of the two unique signals corresponding to the two methoxy groups on the two opposite rings bisected by the mirror plane (e.g., methoxy groups "a" and "e" in Figures 3 and 4).

Saturation of a solution of the new isomer in $\mathrm{C}_{6} \mathrm{D}_{6}$ with 1,1'-bi-2-naphthol $(S)$ resulted only in a very small splitting of a one of the methoxy signals with double intensity, but with (+) 2,2,2trifluoro-1-(9-anthryl)ethanol (Pirkle's reagent) ${ }^{28}$ clear splitting was observed in the three methoxy signals with double intensity, while the two signals integrating for a single methoxy group remained unchanged (Figure 5). 

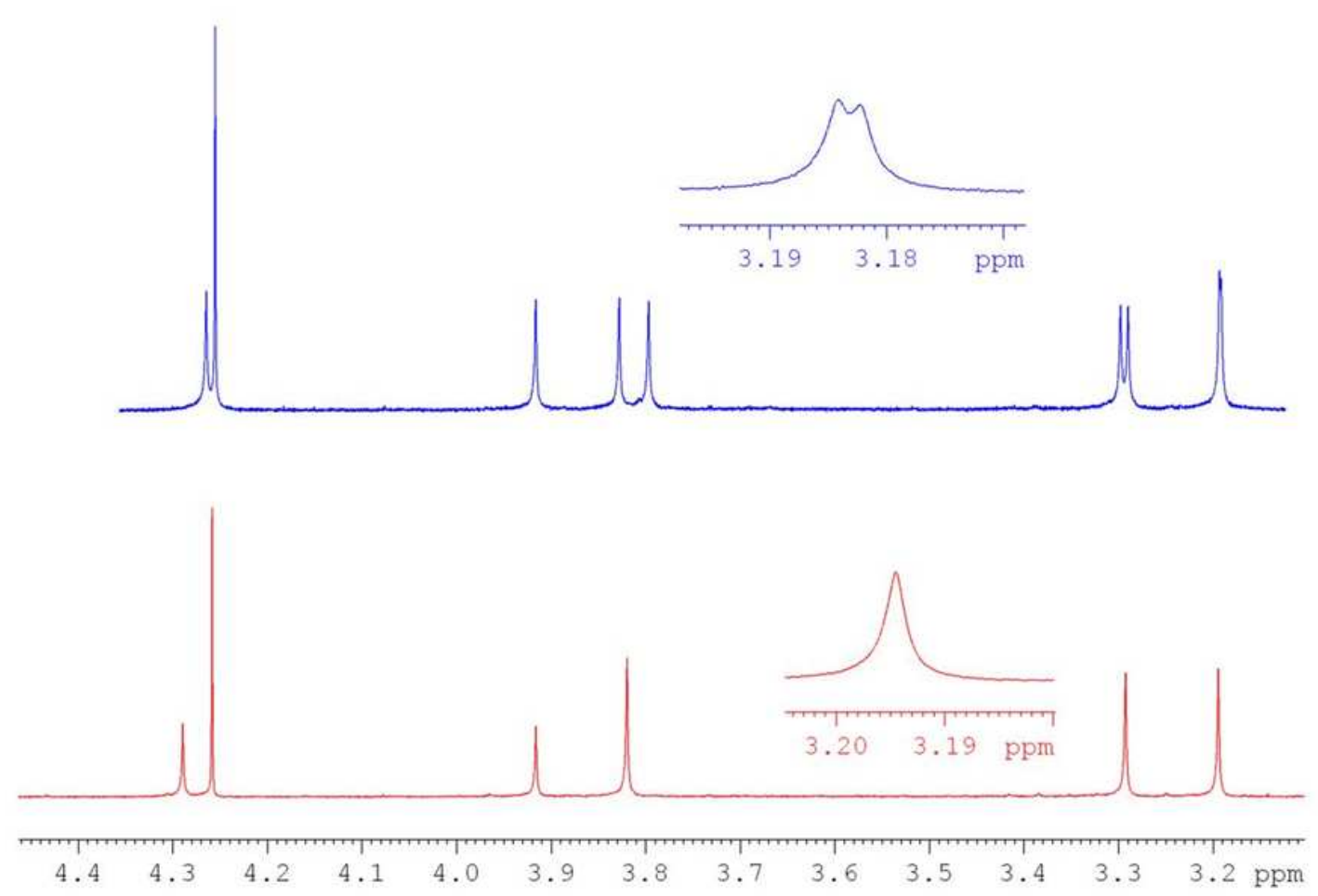

Figure 5. ${ }^{1} \mathrm{H}$ NMR spectrum $\left(500 \mathrm{MHz}, \mathrm{C}_{6} \mathrm{D}_{6}\right.$, rt $)$ of the methoxy region of the kinetic product of the bromination before (bottom, in red) and after (top, in blue) saturation with $(S)(+)-2,2,2-$ trifluoro-1-(9-anthryl)ethanol. The expansion of the top spectrum shows the splitting of the signal at $3.19 \mathrm{ppm}$. The peak at $c a .4 .26 \mathrm{ppm}$ is attributed to residual $\mathrm{CH}_{2} \mathrm{Cl}_{2}$.

Assuming that under the experimental conditions all the enantiotopic methoxy groups are anisochronous, we assign to the kinetic product one of the achiral structures denoted in blue (i.e., the structure of the compound is either $\mathbf{8 c}$ or $\mathbf{8 d}$ ). An unambiguous structural assignment of the configuration could obviously be obtained by X-ray crystallography, but unfortunately all our efforts to grow single crystals of the compound at low temperature in benzene solution (to avoid isomerization) have failed.

At present we are not certain why in the past we obtained in the bromination of 4 in $\mathrm{CH}_{2} \mathrm{Cl}_{2}$ a mixture of isomers, while presently we are obtaining a single isomer, although it could be possible that impurities in the $\mathrm{CH}_{2} \mathrm{Cl}_{2}$ solvent previously used catalyzed the isomerization of the product.

\section{Conclusions}


A previously undetected isomer is the kinetic product of the octabromination of $\mathbf{4}$ under our experimental conditions. On the basis of the NMR pattern of the methoxy signals in the absence and presence of a chiral solvating agent, its structure is assigned as one of the two achiral forms depicted in blue in Figure 1.

\section{Experimental section}

NMR measurements were conducted on a Bruker Avance DRX-400 instrument.

\section{$\mathbf{2 , 8 , 1 4 , 2 0 , 2 6 , 3 2 , 3 8 , 4 4 - O c t a b r o m o - 5 , 1 1 , 1 7 , 2 3 , 2 9 , 3 5 , 4 1 , 4 7 - o c t a - t e r t - b u t y l - 4 9 , 5 0 , 5 1 , 5 2 , 5 3 , 5 4 , - ~}$} 55,56-octamethoxycalix[8]arene (kinetic isomer). A mixture of 4 (2 g, $1.42 \mathrm{mmol})$, NBS (2.07 $\mathrm{g}, 11.4 \mathrm{mmol})$, and dichloromethane $(100 \mathrm{~mL})$ was stirred overnight at room temperature under irradiation with a spot lamp $(60 \mathrm{~W})$. A saturated solution of $\mathrm{Na}_{2} \mathrm{~S}_{2} \mathrm{O}_{5}$ was added $(150 \mathrm{~mL})$, and the organic phase was washed with water and evaporated. Examination of the NMR of the crude product indicated the formation of essentially a single isomer. The residue was dissolved in benzene and after standing for a few days, $1.2 \mathrm{~g} \mathrm{(41 \% )}$ of the product precipitated, mp 189-190 ${ }^{\circ} \mathrm{C} .{ }^{1} \mathrm{H} \mathrm{NMR}\left(\mathrm{CDCl}_{3}, 400 \mathrm{MHz}\right) \delta 8.06(\mathrm{Ar}, \mathrm{d}, J 2.4 \mathrm{~Hz}, 2 \mathrm{H}), 8.04(\mathrm{Ar}, \mathrm{d}, J 2.0 \mathrm{~Hz}, 4 \mathrm{H}), 8.01$ (Ar, d, J 2.4 Hz, 2H), 7.41 (Ar, d, J 2.0 Hz, 2H), 7.20 (Ar, s, 2H), 7.13 (Ar, s, 2H), 7.08 (Ar, d, $J$ $2.4 \mathrm{~Hz}, 2 \mathrm{H}), 6.98(\mathrm{CH}, \mathrm{s}, 2 \mathrm{H}), 6.96(\mathrm{CH}, \mathrm{s}, 2 \mathrm{H}), 6.79(\mathrm{CH}, \mathrm{s}, 2 \mathrm{H}), 6.63(\mathrm{CH}, \mathrm{s}, 2 \mathrm{H}), 4.46(\mathrm{OMe}$, $\mathrm{s}, 3 \mathrm{H}), 4.05(\mathrm{OMe}, \mathrm{s}, 3 \mathrm{H}), 3.95(\mathrm{OMe}, \mathrm{s}, 6 \mathrm{H}), 3.44(\mathrm{OMe}, \mathrm{s}, 6 \mathrm{H}), 2.92(\mathrm{OMe}, \mathrm{s}, 6 \mathrm{H}), 1.45(t-\mathrm{Bu}$, $\mathrm{s}, 18 \mathrm{H}), 1.34(t-\mathrm{Bu}, \mathrm{s}, 18 \mathrm{H}), 1.22(t-\mathrm{Bu}, \mathrm{s}, 18 \mathrm{H}), 1.09(t-\mathrm{Bu}, \mathrm{s}, 9 \mathrm{H}), 0.98(t-\mathrm{Bu}, \mathrm{s}, 9 \mathrm{H}) \mathrm{ppm} .{ }^{13} \mathrm{C}$ NMR $\left(\mathrm{CDCl}_{3}, 100 \mathrm{MHz}\right) \delta 153.0,151.4,150.65,150.60,150.1,148.1,147.9,147.5,147.1$, $135.8,134.9,134.6,133.5,133.3,133.13,133.08,130.6,129.3,128.1,127.5,126.9,126.6$, $126.3,62.5,61.9,61.6,60.7,43.7,42.8,42.4,41.5,35.25,35.16,35.07,34.9,34.8,31.8,31.64$, 31.63, 31.4, 31.3 ppm. HRMS (ESI) $m / z 1954.3323(\mathrm{M}-\mathrm{Br}-\mathrm{H})$. Calcd for $\mathrm{C}_{96} \mathrm{H}_{121} \mathrm{O}_{8} \mathrm{Br}_{7}$ : 1954.3345 .

\section{Acknowledgment}

This research was supported by the Israel Science Foundation (grant No. 104/10).

\section{References and notes}

1. Calixarenes, a Versatile Class of Macrocyclic Compounds; Vicens, J.; Böhmer, V., Eds., Kluwer: Dordrecht, 1991. http://dx.doi.org/10.1016/S0040-4020(01)91215-3

2. Shinkai, S. Tetrahedron 1993, 49, 8933. 
http://dx.doi.org/10.1002/anie.199507131

3. Böhmer, V. Angew. Chem., Int. Ed. Engl. 1995, 34, 713.

4. Gutsche, C. D. Aldrichimica Acta 1995, $28,1$.

5. Pochini, A.; Ungaro, R. in Comprehensive Supramolecular Chemistry, Vögtle, F. Vol. Editor, Pergamon Press, Oxford, UK, 1996, Vol. 2, 103.

6. Gutsche, C. D. Calixarenes Revisited, Royal Society of Chemistry, Cambridge, 1998.

7. Calixarenes 2001, Asfari, Z.; Böhmer, V.; Harrowfield, J.; Vicens, J.; Eds., Kluwer Academic Publishers, Dordrecht, 2001.

8. Böhmer, V. in The Chemistry of Phenols, Rappoport, Z., Ed., Wiley, Chichester, 2003, ch. 19.

9. Gutsche, C. D. Calixarenes. An Introduction. 2nd Edition, Royal Society of Chemistry, Cambridge, 2008.

10. Tabatabai, M.; Vogt, W.; Böhmer, V. Tetrahedron Lett. 1990, 31, 3295. http://dx.doi.org/10.1016/S0040-4039(00)89047-4

11. Sartori, G.; Maggi, R.; Bigi, F.; Arduini, A.; Pastorio, A.; Porta, C. J. Chem. Soc., Perkin Trans. 1 1994, 1657. http://dx.doi.org/10.1039/p19940001657

12. Biali, S. E.; Böhmer, V.; Cohen, S.; Ferguson, G.; Grüttner, C.; Grynszpan, F.; Paulus, E. F.; Thondorf, I.; Vogt, W. J. Am. Chem. Soc. 1996, 118, 12938. http://dx.doi.org/10.1021/ja960883n

13. Bergamaschi, M.; Bigi, F.; Lanfranchi, M.; Maggi, R.; Pastorio, A.; Pellinghelli, M. A.; Peri, F.; Porta, C.; Sartori, G. Tetrahedron 1997, 53, 13037. http://dx.doi.org/10.1016/S0040-4020(97)00827-2

14. Böhmer, V. Liebigs Ann./Recueil 1997, 2019.

15. Middel, O.; Greff, Z.; Taylor, N. J.; Verboom, W.; Reinhoudt, D. N.; Snieckus, V. J. Org. Chem. 2000, 65, 667. http://dx.doi.org/10.1021/j0990976y

16. Scully, P. A.; Hamilton, T. M.; Bennett, J. L. Org. Lett. 2001, 3, 2741. http://dx.doi.org/10.1021/o1016346b

17. Gopalsamuthiram, V.; Predeus, A. V.; Huang, R. H.; Wulff, W. D. J. Am. Chem. Soc. 2009, $131,18018$. http://dx.doi.org/10.1021/ja905990u

18. Sliwa, W.; Deska, M. Arkivoc, 2012 (i), 173. http://dx.doi.org/10.3998/ark.5550190.0013.106

19. Columbus, I.; Biali, S. E. Org. Lett. 2007, 9, 2927. http://dx.doi.org/10.1021/o10713178

20. Columbus, I.; Biali, S. E. J. Org. Chem. 2008, 73, 2598. http://dx.doi.org/10.1021/jo702474n

21. Kogan, K.; Columbus, I.; Biali, S. E. J. Org. Chem. 2008, 73, 7327. 
http://dx.doi.org/10.1021/jo801187z

22. Kogan, K.; Biali, S. E. J. Org. Chem. 2009, 74, 7172.

http://dx.doi.org/10.1021/jo901450x

23. Kogan, K.; Itzhak, N.; Biali, S. E. Supramol. Chem. 2010, 22, 704.

http://dx.doi.org/10.1080/10610278.2010.500728

24. Klenke, B.; Näther, C.; Friedrichsen, W. Tetrahedron Lett. 1998, 39, 8967.

http://dx.doi.org/10.1016/S0040-4039(98)02056-5

25. Kumar, S. K.; Chawla, H. M.; Varadarajan, R. Tetrahedron Lett. 2002, 43, 7073. http://dx.doi.org/10.1016/S0040-4039(02)01548-4

26. Fischer, C.; Lin, G.; Seichter, W.; Weber, E. Tetrahedron Lett. 2013, 54, 2187. http://dx.doi.org/10.1016/j.tetlet.2013.02.061

27. Kogan, K.; Biali, S. E. J. Org. Chem., 2011, 76, 7240.

http://dx.doi.org/10.1021/jo2009643

28. Pirkle, W. H.; Sikkenga, D. L.; Pavlin, M. S. J. Org. Chem. 1977, 42, 384.

http://dx.doi.org/10.1021/jo00422a061 